\title{
CABO FRIO - UM ENCLAVE SEMIÁRIDO NO LITORAL ÚMIDO DO ESTADO DO RIO DE JANEIRO: RESPOSTAS DO CLIMA ATUAL E DA VEGETAÇÃO PRETÉRITA ${ }^{1}$
}

\author{
Heloisa Helena Gomes Coe* \\ Cacilda Nascimento de Carvalho**
}

\begin{abstract}
Resumo: Localizada na costa nordeste do Estado do Rio de Janeiro, Brasil, a região de Cabo Frio tem sido considerada um "enclave" fitogeográfico, com um clima mais seco que o restante do litoral fluminense, reduto de vegetação semelhante à caatinga, dominada por florestas xeromórficas, Cactaceae e Bromeliaceae. Objetivando contribuir para esta discussão de modo singular, este trabalho faz análises multivariadas de similaridade de variáveis do clima atual, comparando Cabo Frio com seu entorno mais úmido e com a caatinga do Nordeste brasileiro, e estuda possíveis variações da paleovegetação na região, utilizando como indicadores os fitólitos. Conclui-se que o clima de Cabo Frio se assemelha mais à caatinga que ao seu entorno, e que a vegetação, desde 13.000 anos cal AP, foi sempre de tipo pouco arbórea.
\end{abstract}

Palavras-chave: Cabo Frio, clima, enclave fitogeográfico, ressurgência, análises multivariadas, fitólitos.

\section{CABO FRIO - AN ENCLAVE IN SEMI ARID COASTAL MOIST OF RIO DE JANEIRO STATE: INFLUENCES OF CLIMATE AND PRESENT PAST VEGETATION}

\begin{abstract}
Located on the northeast coast of the State of Rio de Janeiro, Brazil, Cabo Frio region has been considered a phytogeographical enclave, with a drier climate than the rest of this coast, a redoubt for the "caatinga" like vegetation, dominated by xeromorphic forests, Cactaceae and Bromeliaceae. In order to contribute to this discussion in a singular way, this work makes multivariate analysis of similarity of variables of the current climate, comparing Cabo Frio with its more humid surroundings and the "caatinga" of Brazilian northeast. We also analyze possible changes in regional palaeovegetation, using phytoliths as proxy. We conclude that Cabo Frio has a climate more similar to the "caatinga" than to its surrounding, and that the vegetation, from 13,000 years cal BP, did not present major changes.
\end{abstract}

Key Words: Cabo Frio, climate, phytogeographical enclave, upwelling, multivariate analysis, phytoliths.

\section{Introdução}

A região de Cabo Frio apresenta peculiaridades geoecológicas, sendo considerada um enclave fitogeográfico no litoral do Rio de Janeiro. Este enclave seria explicado pelo clima semi-árido local de Cabo Frio, ligado, entre outros fatores, à presença de uma ressurgência costeira e ao regime de ventos da região, o qual pode ser perturbado por eventos El Niño.
Algumas hipóteses foram propostas para explicar a dinâmica da vegetação da região durante o Quaternário. Ab' Saber (1977), baseado em estudos da flora e fauna atuais e em evidências geomorfológicas, acredita que, com as mudanças ambientais ocorridas na última glaciação, as caatingas se estenderam por grande parte do Brasil Tropical Atlântico, permanecendo, em alguns locais, desde

\footnotetext{
* Professora Adjunta do Departamento de Geografia da Faculdade de Formação de Professores da UERJ. Email: heloisacoe@yahoo.com.

** Professora Adjunta aposentada do Departamento de Geoquímica da UFF. E-mail: cacilda.carvalho@terra.com.br

${ }^{1}$-Este artigo é um avanço no trabalho apresentado no VI Seminário Latino-americano de Geografia Física, Coimbra, 2010, e publicado em http://www.uc.pt/fluc/cegot/VISLAGF/actas/tema3/heloisa
} 
então, como mini ou meso-redutos onde dominam cactáceas e bromeliáceas. Cabo Frio seria um testemunho paleoclimático do clima seco e frio do último Período do Quaternário, tendo sido postulado que a área de caatinga antes ocupava um espaço muito maior. Prado (1991, 2000), através de um estudo botânico, estabeleceu um modelo de expansão das florestas secas sazonais na América do Sul, no qual identifica três núcleos de distribuição: 1) as caatingas do Nordeste do Brasil; 2) o sistema florestal da região fluvial do Paraná-Paraguai; e 3 ) as florestas do piemonte subandino do sudoeste (SO) da Bolívia e noroeste (NW) da Argentina. Estes três núcleos seriam ligados por duas rotas de conexão (NO-SE e NE-SO). A rota nordeste (NE)-SO atravessaria 0 Estado do Rio de Janeiro. Lima (2000), através da identificação de elementos florísticos típicos da caatinga em algumas partes do litoral Rio de Janeiro (principalmente em Cabo Frio), reforça esse último modelo: o grande número de espécies endêmicas da floresta seca no Rio de Janeiro seria ligado a seu isolamento durante o Holoceno.

Araujo (2000), também através de estudos botânicos, explica o desenvolvimento da flora das restingas ao longo de todo o litoral brasileiro em períodos de regressões marinhas (Pleistoceno e Holoceno). A diferença de composição florística das restingas atuais se explicaria por uma compressão desta flora durante transgressões marinhas em terraços marinhos descontínuos.

As características morfológicas, químicas e mineralógicas dos solos da região sugerem um regime pedogenético particular, com a possibilidade de representarem pedoambientes outrora mais amplos e hoje isolados, mantidos graça às peculiaridades morfoclimáticas regionais (Ibraimo et al., 2004).

O objetivo deste trabalho é contribuir de modo singular para a discussão sobre o fato de a região ser ou não um enclave, através de análises multivariadas de similaridade de variáveis do clima atual, comparando Cabo Frio com seu entorno mais úmido e com a caatinga do Nordeste brasileiro. Além disso, busca-se inferir possíveis variações paleoclimáticas na região, através de reconstituições de sua vegetação que utilizaram como indicadores os fitólitos.

\section{A ÁREA DE ESTUDOS}

Para fins de caracterização ambiental, optou-se pela delimitação climática e fisionômica em uma unidade geográficoambiental que inclui no conceito de Região de Cabo Frio os municípios de Arraial do Cabo, Búzios, Cabo Frio, Iguaba, São Pedro da Aldeia e Araruama. Abrange uma área de aproximadamente $1.500 \mathrm{~km}^{2}$ e está localizada entre as coordenadas $22^{\circ} 30^{\prime}$ $23^{\circ} 00^{\prime} \mathrm{S}$ e $41^{\circ} 52^{\prime}-42^{\circ} 19^{\prime} \mathrm{W}$, com altitudes que variam desde o nível do mar até cerca de $300 \mathrm{~m}$ (figura1).

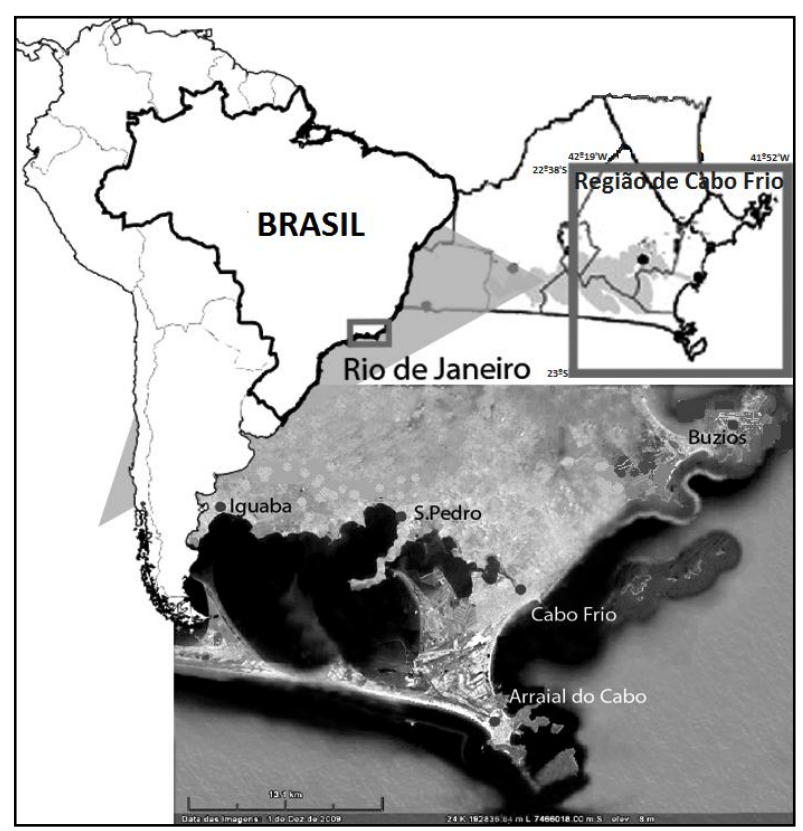

Figura 1: Localização da área de estudo (Fonte: modificado de Google Earth, 2009) 
A região apresenta um complexo quadro geológico e geomorfológico, cuja litologia é composta principalmente por paragnaisses originados de depósitos marinhos pelíticos (Schmitt et al., 2004), muito antigos e intemperizados, areias e materiais argilosos que formam espessos mantos de alteração, onde concreções ferruginosas e linhas de pedra podem ser encontradas. Esta parte do litoral fluminense, também conhecida como Região dos Lagos, é caracterizada por grandes lagoas de água salgada ou salobra que foram isoladas do oceano por longos pontais distanciados do litoral e são, em grande parte, modeladas pelas variações do nível relativo do mar durante o Quaternário.

Os solos na região são pouco desenvolvidos, normalmente rasos, com características morfológicas, químicas e mineralógicas que sugerem um regime pedogenético particular (Camargo, 1979; Moniz et al., 1990). Apresentam considerável variabilidade vertical e horizontal, sendo fortemente influenciados por fatores climáticos e topográficos. Os solos sob caatinga hipoxerófila constituem o substrato fundamental a este ambiente sui generis (Ibraimo et al., 2004).

A principal característica oceanográfica da região de Cabo Frio é a ocorrência de uma ressurgência costeira onde as águas frias e ricas em nutrientes da Água Central do Atlântico Sul (ACAS) afloram na plataforma continental, devido à mudança brusca de orientação da costa, que passa de uma direção mais ou menos norte-sul a uma leste-oeste; ao deslocamento sazonal do eixo da Corrente do Brasil (CB), que é desviado ao largo no verão; e, sobretudo, ao regime de ventos da região (Barbosa, 2003) (figura 2).

De setembro a abril, a CB está afastada da costa e a ACAS ultrapassa o talude continental e invade o fundo da plataforma, onde permanece. Durante os meses de primavera e verão, a atuação direta dos ventos locais do setor leste, de alta frequência e intensidade, promove a subida da ACAS à superfície (Valentin, 1994).

O ciclo de ressurgência é interrompido mais frequentemente durante o inverno, quando os ventos SW prevalecem, na passagem de frentes frias, proporcionando 0 empilhamento das águas superficiais na costa, fazendo com que a ACAS retorne às profundezas. A intensificação da ressurgência na região de Cabo Frio induz a uma redução na precipitação e na cobertura de nuvens, levando, consequentemente, a um aumento na insolação e na aridez climática, evaporação (compensando o fato que esta seria reduzida pelas temperaturas mais baixas das águas oceânicas) e salinidade das lagoas.

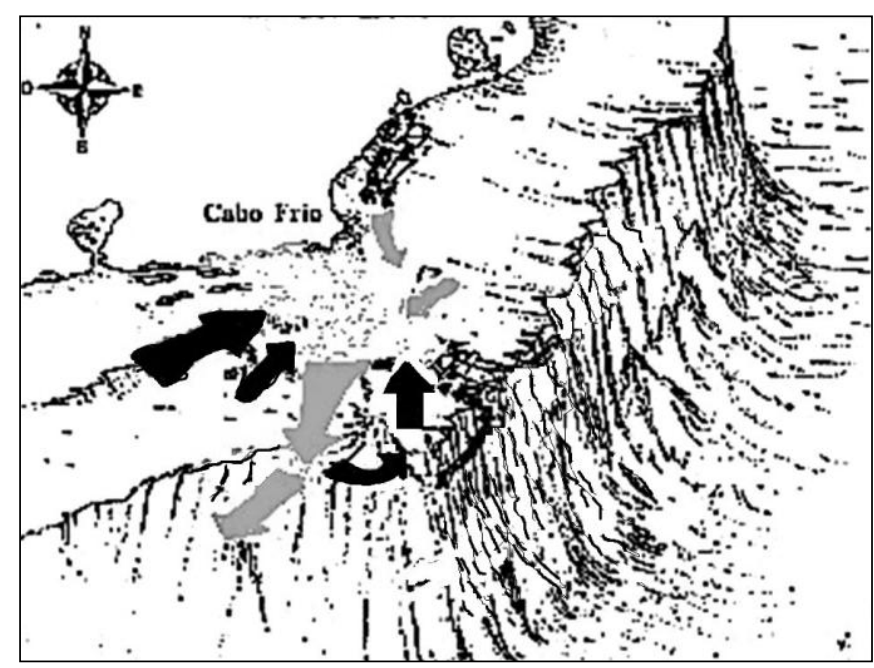

Figura 2: Circulação das massas de água na região de Cabo Frio. As setas mais claras representam a circulação superficial, e as setas escuras representam a circulação do fundo (Fonte: modificado de Ortega,1996).

\section{A GeOeCOlOgiA, $O$ CLIMA E A VEGETAÇÃO DE CABO FRIO}

A região de Cabo Frio possui um clima sui generis para o litoral sudeste brasileiro, com pluviosidade reduzida em 
relação às regiões contíguas, destacando-se

do

conjunto

tropical

úmido por apresentar um clima local classificado como semiárido quente, uma variação do Bsh de Köppen (Barbiére, 1975). Caracteriza-se por fracas precipitações (em média em torno de 770 a $854 \mathrm{~mm} / \mathrm{ano}$ ) e por uma taxa de evaporação compreendida entre 1200 e 1400 mm/ano (Barbiére, 1984), notadamente em período estival. A temperatura média é ligeiramente superior a $21^{\circ} \mathrm{C}$ de junho a setembro e varia entre 23 e $25^{\circ} \mathrm{C}$ de novembro a abril, não apresentando, portanto, grande amplitude térmica anual. A insolação varia entre 200 e 240 h/ mês (Barbiére, 1984), com exceção do período entre setembro e novembro, quando varia de 150 a $190 \mathrm{~h} /$ mês (tabela 1).

A região é caracterizada pela existência de duas estações bem marcadas: uma estação estival úmida e uma invernal seca (Nimer, 1989). O verão é caracterizado pela predominância de ventos de direção $\mathrm{NE}$, enquanto que o inverno é marcado por períodos descontínuos de ventos do S-SW, ligados à passagem de sistemas frontais provenientes de médias latitudes.

Tabela 1: Cabo Frio - Normais mensais de 1961 a 1990 (Fonte INMET, 2005) Estação Climatológica de CABO FRIO (Álcalis)/RJ Lat : $22^{\circ} 59^{\prime} \mathrm{S}$ Long : $42^{\circ} 02^{\prime} \mathrm{W}$ Alt : 7,00 m

\begin{tabular}{cccccc}
\hline MÊS & $\begin{array}{c}\text { EVAPORAÇÃO } \\
(\mathrm{mm})\end{array}$ & $\begin{array}{c}\text { INSOLAÇÃO } \\
(\mathrm{hs})\end{array}$ & $\begin{array}{c}\text { PRECIPITAÇÃO } \\
(\mathrm{mm})\end{array}$ & $\begin{array}{c}\text { TEMPERATURA } \\
\text { MÉDIA } \\
\text { COMPENSADA* } \\
\left({ }^{\circ} \mathrm{C}\right)\end{array}$ & $\begin{array}{c}\text { UMIDIDADE } \\
\text { RELATIVA } \\
(\%)\end{array}$ \\
\hline JAN & 80,9 & 239,8 & 78,1 & 25,1 & 82,0 \\
FEV & 78,5 & 235,2 & 44,1 & 25,4 & 82,0 \\
MAR & 77,4 & 227,8 & 52,8 & 25,4 & 82,0 \\
ABR & 78,1 & 197,7 & 78,3 & 24,3 & 80,0 \\
MAI & 71,2 & 214,3 & 69,1 & 22,8 & 81,0 \\
JUN & 67,5 & 201,1 & 43,9 & 21,6 & 81,0 \\
JUL & 78,3 & 218,5 & 44,7 & 21,3 & 80,0 \\
AGO & 79,8 & 203,7 & 36,1 & 21,2 & 81,0 \\
SET & 83,3 & 156,2 & 61,0 & 21,3 & 81,0 \\
OUT & 78,7 & 179,1 & 80,7 & 22,2 & 82,0 \\
NOV & 79,8 & 189,6 & 81,0 & 23,3 & 82,0 \\
DEZ & 78,6 & 201,6 & 101,1 & 24,5 & 82,0 \\
\hline
\end{tabular}

*Temperatura média compensada: média de três leituras (9h, 15h e 21h, por exemplo) mais a máxima e a mínima do dia

A figura 3 apresenta um mapa das isoietas do setor leste do litoral do Estado do Rio de Janeiro. As estações de Cabo Frio, Iguaba Grande e Saquarema registram precipitações anuais inferiores a $1.000 \mathrm{~mm}$, enquanto outras, a pouco mais de $100 \mathrm{~km}$ de distância, podem receber até mais de $2.500 \mathrm{~mm}$ anuais de chuva.

No Estado do Rio de Janeiro, Nimer (1989) distingue a Serra do Mar, com uma vegetação superúmida, que separa a baixada litorânea quente e úmida do planalto interiorano, onde são bem mais definidas as épocas de secas e de chuvas. Na parte norte do estado, o clima é influenciado pela ascensão de ar quente dos vales e da baixada, na margem esquerda do rio Paraíba do Sul. Davis e Naghettini (2001) reforçam os comentários de Nimer (1989), destacando que os níveis 
mais elevados da Serra da Mantiqueira recebem em média entre 2.000 a $2.500 \mathrm{~mm}$ de chuva durante o ano e na Serra do Mar os valores variam entre 2.000 a $4.500 \mathrm{~mm}$.

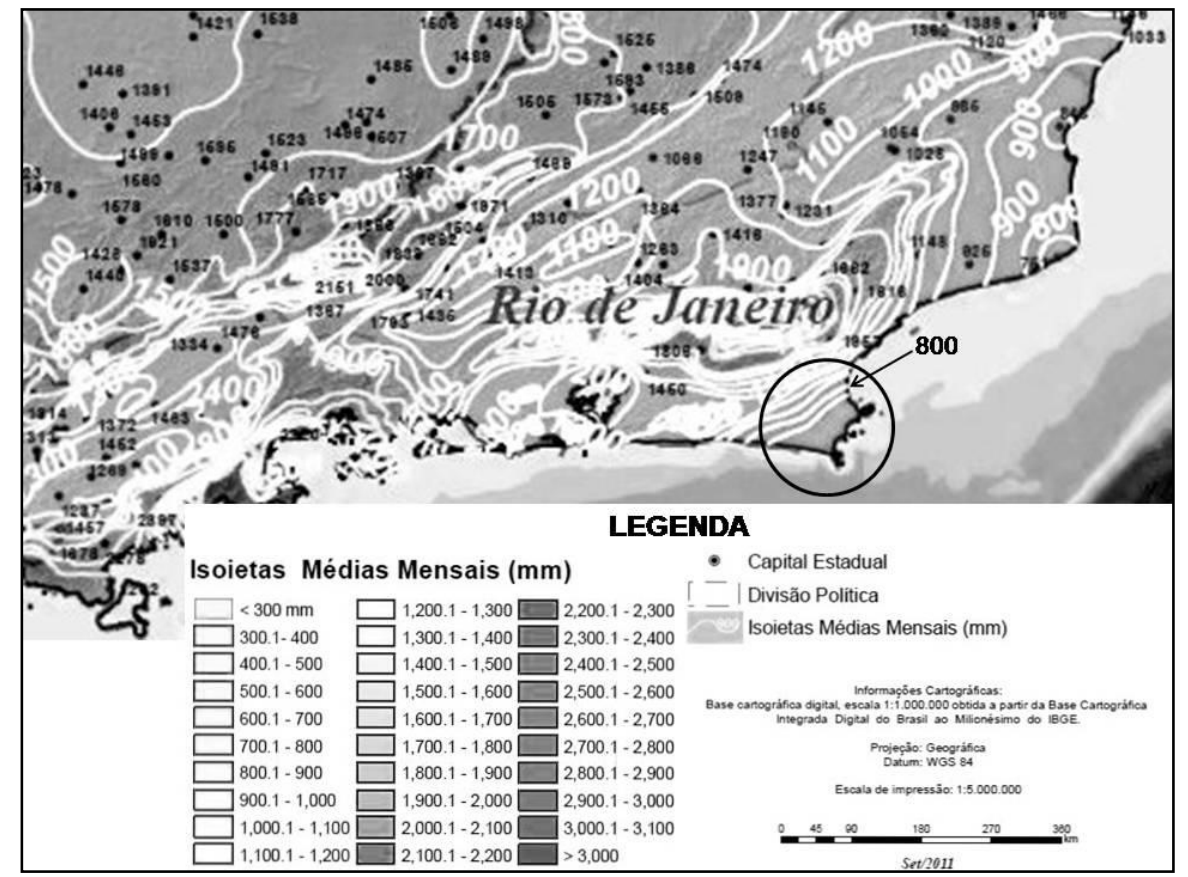

Figura 3: Mapa das isoietas do Estado do Rio de Janeiro, com destaque para a isoieta de $800 \mathrm{~mm}$ e a Região dos Lagos (Modificado de http://www.cprm.gov.br/publique/media/Isoietas_Totais_Anuais_1977-2006,_2011)

As peculiaridades geoecológicas de Cabo Frio condicionam diversas formações vegetais, com muitas espécies endêmicas e raras. A região abriga $65 \%$ das espécies indicadas por Araujo (2000) como endêmicas ao Estado do Rio de Janeiro, uma porcentagem muito maior que qualquer outra região de restinga.

A condição climática mais seca da região define formações vegetais que fogem do aspecto exuberante que as florestas de encosta do Estado do Rio de Janeiro costumam apresentar (Farág, 1999). As matas da região foram classificadas como "uma disjunção fisionômico-ecológica da estepe nordestina" (Ururahy, 1987) ou como "floresta seca" (Mooney et al., 1995). Araujo (1997) distingue três unidades fisionômicas na região: (1) planícies costeiras (praia, dunas e terras baixas, áreas alagadas, lagoas e depósitos aluviais); (2) baixos morros de Cabo Frio e de Búzios e ilhas costeiras; (3) morros continentais até $300 \mathrm{~m}$ (figura 4).
Os maciços litorâneos da região estão cobertos por uma mata baixa ( $3 \mathrm{~m}$ de altura em média), nas vertentes mais expostas aos ventos marinhos, composta de árvores densas de troncos finos. Em locais mais protegidos do vento, em grotões úmidos ou nas serras mais afastadas do mar, a vegetação assume um porte mais robusto, semelhante à Mata Atlântica baixo-montana (Rizzini, 1979).

$\mathrm{Na}$ planície colúvio-aluvial, a vegetação caracteriza-se por uma formação florestal com grande predominância de espécies caducifólias, o que Ihe proporciona, durante os meses mais secos do ano (junho /agosto), uma aparência acinzentada. Observa-se nas florestas xeromórficas de pequeno porte das escarpas próximas ao mar, desde a Ilha de Cabo Frio até Búzios, uma composição florística única ao longo de toda a costa (Araujo, 1997). O cacto colunar Pilosocereus ulei, endêmico da região (Rizzini, 1979), confere uma aparência 
característica de ambientes áridos nas épocas mais secas do ano, assemelhando-se ao ambiente da caatinga.

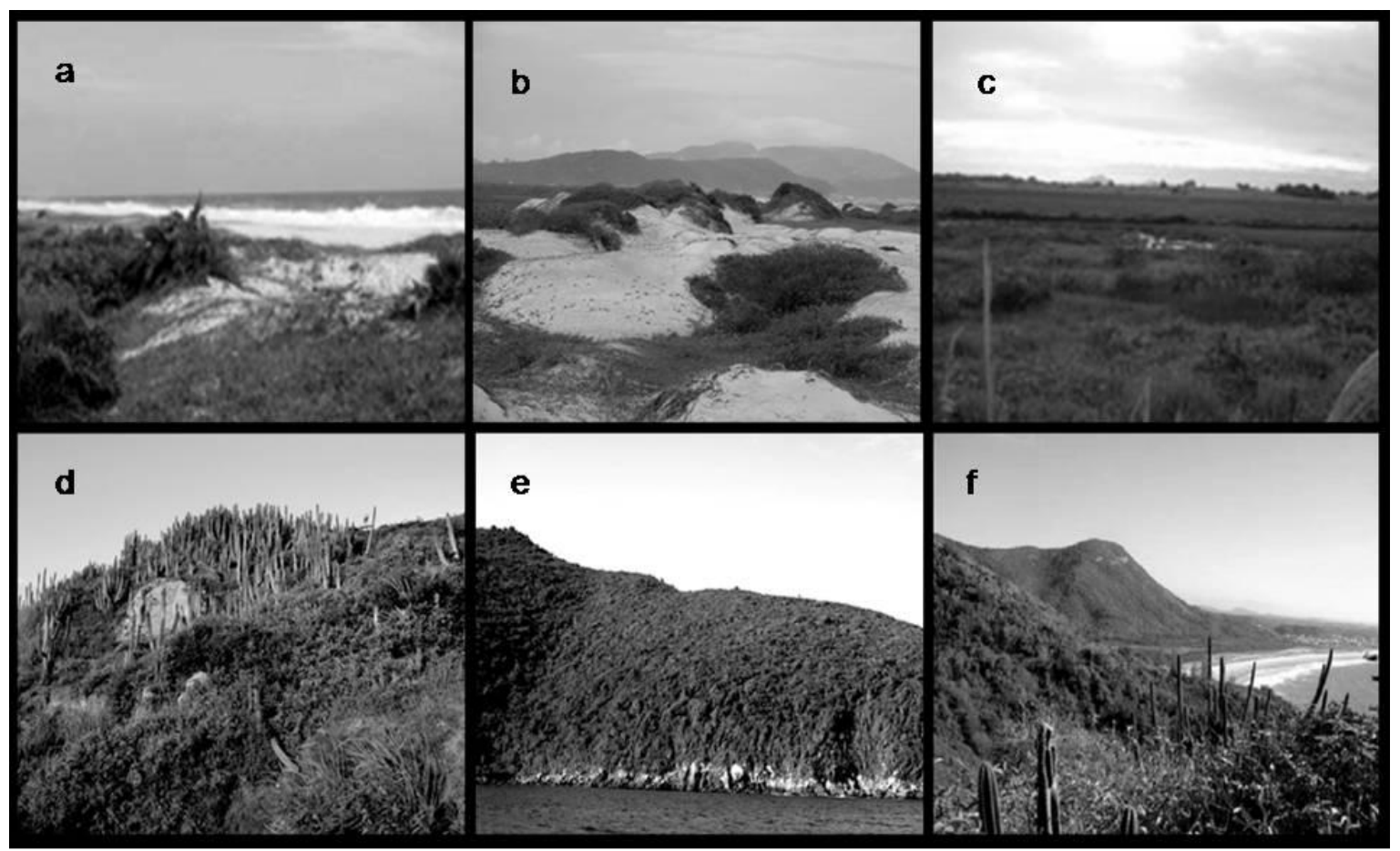

Figura 4: Vegetação em diferentes unidades fisionômicas da região de Cabo Frio: a) Praias; b) Dunas; c) Áreas alagadas; d) Baixos morros; e) Ilhas costeiras; f) Morros continentais de até $300 \mathrm{~m}$ (Fotos Coe, 2007)

\section{MÉTODOS}

Para comparar o clima de Cabo Frio com o de seu entorno, estiveram disponíveis dados de precipitação em 15 estações meteorológicas localizadas a menos de 150 km de Cabo Frio (tabela 2), abrangendo períodos de observação maiores que 14 anos ininterruptos, mas em anos diferentes (entre 1935 e 1993, dependendo da estação). Para a região da caatinga (34 estações meteorológicas distribuídas em todos os estados do NE e Bahia) foi possível usar dados de evaporação (Eva); insolação (Ins); precipitação $(P)$; temperatura média (Tar) e umidade relativa (UR), coletados em um mesmo período de 30 anos (de 1961 a 1990). Assim, após uma análise exploratória dos dados, e comparação entre médias de precipitação, fez-se análise multivariada de grupamento, com matriz de distância euclidiana entre os locais, amalgamação dos grupos pelo método da variância mínima, utilizando as variáveis padronizadas. Para contornar o fato de que as séries locais são temporalmente heterogêneas foram privilegiados testes não-paramétricos $\mathrm{e}$ padronização de variáveis.

A região de Cabo Frio foi também objeto de estudos paleoambientais (Coe, 2009; Coe et al., 2007, 2008, 2009, 2012), a fim de inferir mudanças na sua vegetação e, consequentemente do clima, durante o Quaternário. Para tal, foram utilizados como indicadores silicofitólitos extraídos de quatro perfis de solo desenvolvidos sobre gnaisse; para fins de referência, também se coletaram amostras da camada mais superficial, diretamente abaixo da serrapilheira, sob os quatro tipos de cobertura vegetal mais representativos na região: mata seca, mata úmida, caatinga hipoxerófila e brejos. A partir das análises fitolíticas foram calculados 
índices de densidade arbórea ( $D / P=$ fitólitos de dicotiledôneas lenhosas/ fitólitos de Poaceae) e de estresse hídrico (Bremond et al., 2005; Coe, 2009; Coe et al., 2008, 2011, 2012). Os resultados foram complementados por análises isotópicas $\left(\delta^{13} \mathrm{C}\right)$, realizadas no CENA, SP, e dos fenóis de ligninas, realizadas no Departamento de Geoquímica da UFF. As amostras foram datadas por ${ }^{14} \mathrm{C}$ AMS nos laboratórios da Universidade de Irvine, Califórnia.

\section{APRESENTAÇÃO E DISCUSSÃo dOS RESULTADOS}

\section{QUADRO CLIMÁTICO}

Precipitação: Comparando-se uma série de dados de algumas estações meteorológicas do Estado do Rio de Janeiro com outras da região da caatinga (Nordeste do Brasil e norte de Minas Gerais) (figura 5), observa-se que em Cabo Frio a precipitação média é de 750 mm/ano (Tabela 2), enquanto nas demais áreas do Estado as precipitações são superiores a $1100 \mathrm{~mm} / \mathrm{ano}$, podendo atingir quase $2000 \mathrm{~mm}$ /ano nas áreas de maior pluviosidade (Angra dos Reis). Entretanto, várias estações da caatinga apresentam totais anuais semelhantes aos de Cabo Frio, em torno de 800 $\mathrm{mm} / \mathrm{ano}$, como se pode observar na figura 6 .

Tabela 2: Totais anuais de chuva em algumas estações no Estado do Rio de Janeiro (Cabo Frio e seu entorno) e na área de ocorrência da caatinga no Nordeste do Brasil

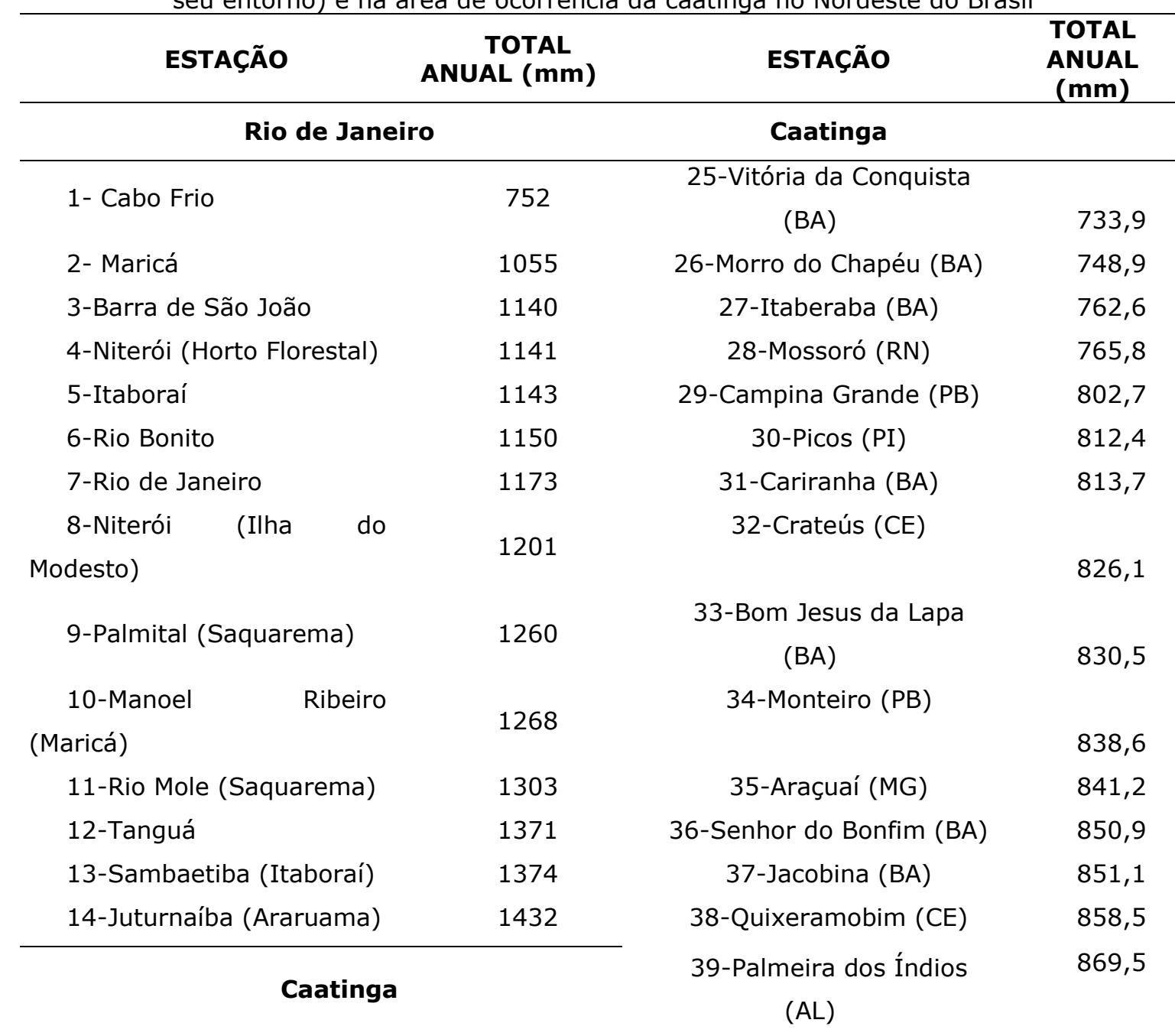

1-Este artigo é um avanço no trabalho apresentado no VI Seminário Latino-americano de Geografia Física, Coimbra, 2010, e publicado em http://www.uc.pt/fluc/cegot/VISLAGF/actas/tema3/heloisa 


\begin{tabular}{lcccc}
\hline 15-Cabrobó (PE) & 517,4 & & 40-Garanhuns (PE) & 870,3 \\
16-Paulo Afonso (BA) & 582,9 & & 41-Pedra Azul (MG) & 877 \\
17-Paulistana (PI) & 597,3 & & 42-Caetité (BA) & 890,8 \\
18-Macau (RN) & 599,7 & & 43-Apodi (RN) & 920,4 \\
19-Petrolina (PE) & 609,8 & & 44-Tauá (CE) & 925,7 \\
20-Campos Sales (CE) & 619,2 & & 45-Sobral (CE) & 960,4 \\
21-Barra (BA) & 661,1 & & 46-Barbalha (CE) & 1001,4 \\
22-Arco Verde (PE) & 694,2 & & 47-Floriano (PI) & 1102,7 \\
23-Remanso (BA) & 696 & 48-Bom Jesus do Piauí & \\
& 728,3 & (PI) & 1156,7 \\
24-Florania (RN) & \multicolumn{2}{c}{} \\
\hline
\end{tabular}

Insolação: Os dados do total anual de horas de insolação de Cabo Frio também são superiores aos das outras estações fluminenses (cerca de 2500 h/ano contra 1700 a 2200 h/ano), ficando, entretanto, na média das estações da caatinga. (figura 7). Considerando que há grande diferença latitudinal entre as duas regiões estudadas, a semelhança de insolação entre Cabo Frio, outras estações do RJ e as da Caatinga nordestina, pode estar associada à umidade relativa do ar e à frequência de cobertura de nuvens. Esta hipótese poderia ser corroborada com os dados de nebulosidade das estações que, entretanto, não estão disponíveis.

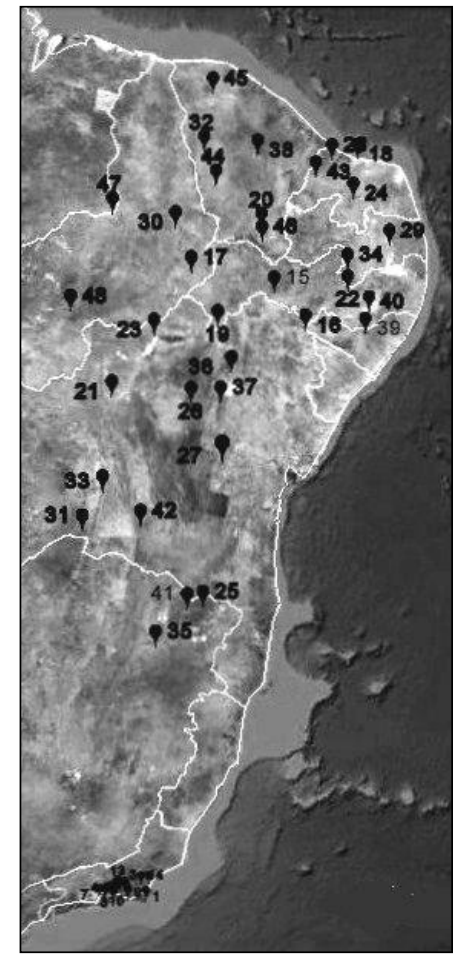

Figura 5: Localização das estações meteorológicas do Estado do Rio de Janeiro e na área de ocorrência da caatinga no Nordeste do Brasil (modificado de Google Earth, 2012)

Temperatura média anual: a temperatura média anual (média das temperaturas médias compensadas dos 12 meses) de Cabo Frio, no período de 1961 a 1990 , foi de $23,2^{\circ} \mathrm{C}$. As diferenças de temperatura entre Cabo Frio e as estações da área da caatinga não são significativas (teste Mann-Whitney, $a / 2=2,5$ ), servindo também para confirmar a semelhança entre os locais. 


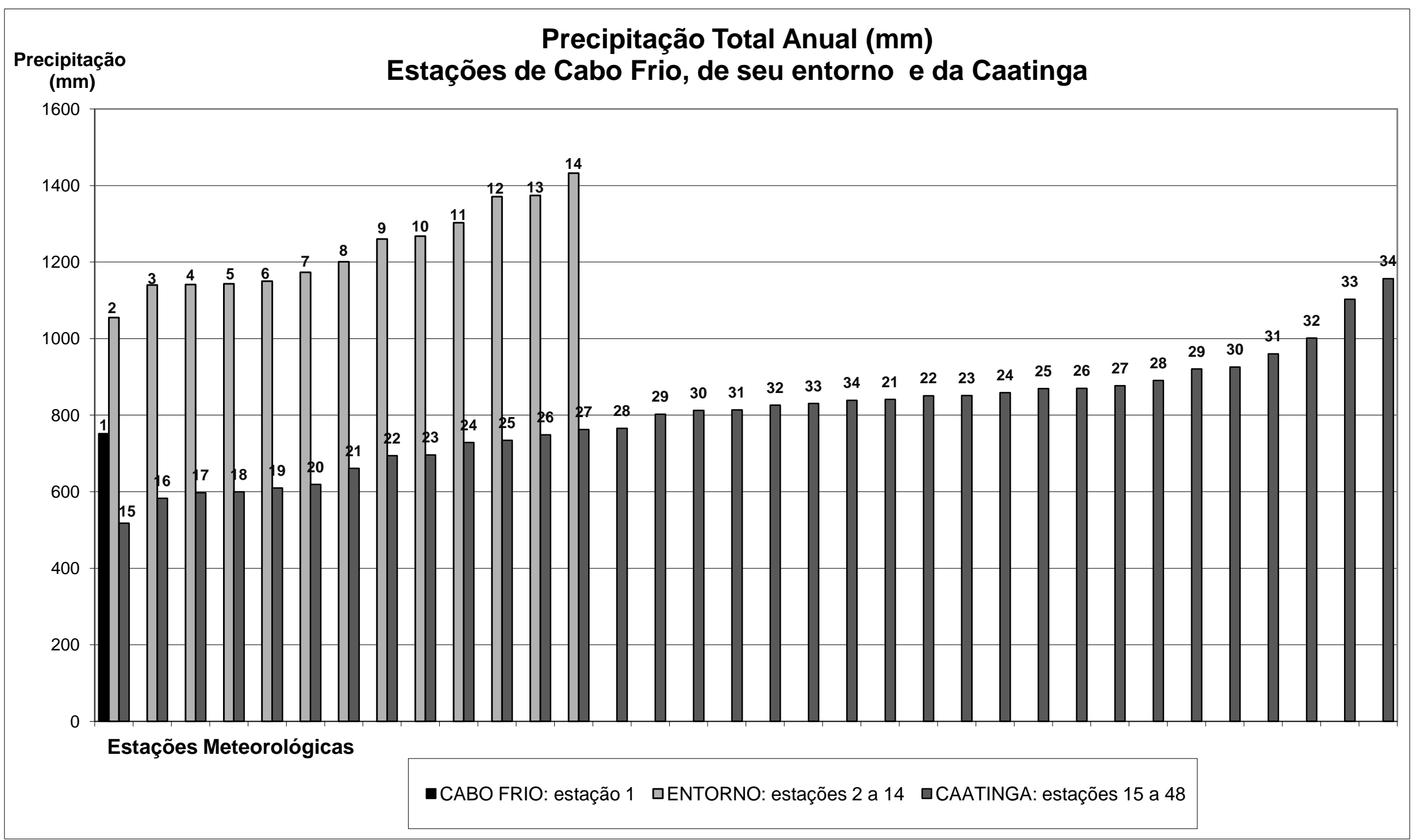

Figura 6: Total anual (mm) de precipitação de estações meteorológicas do entorno de Cabo Frio e da caatinga (Fonte: INMET, 2005) 


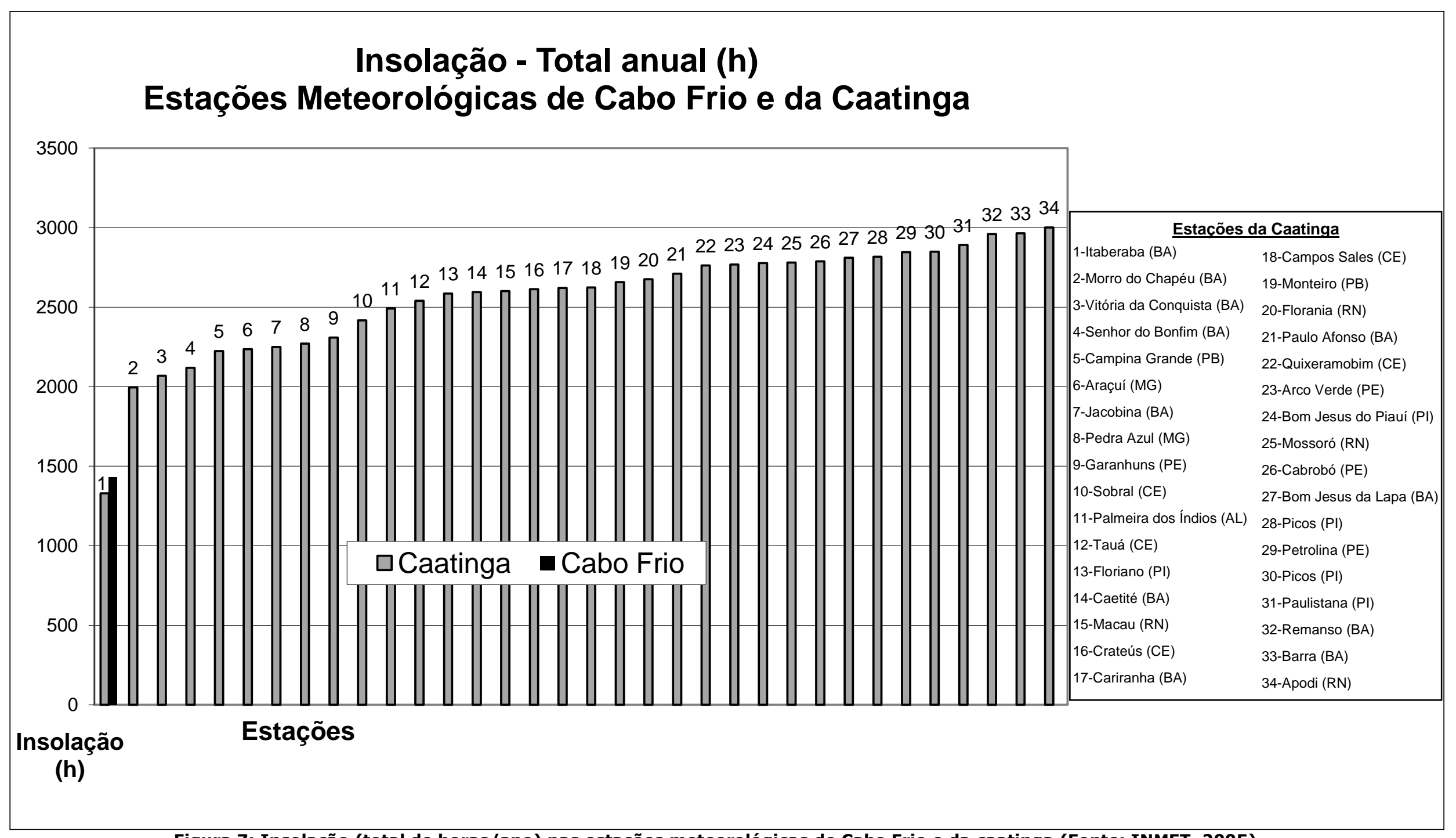

Figura 7: Insolação (total de horas/ano) nas estações meteorológicas de Cabo Frio e da caatinga (Fonte: INMET, 2005) 


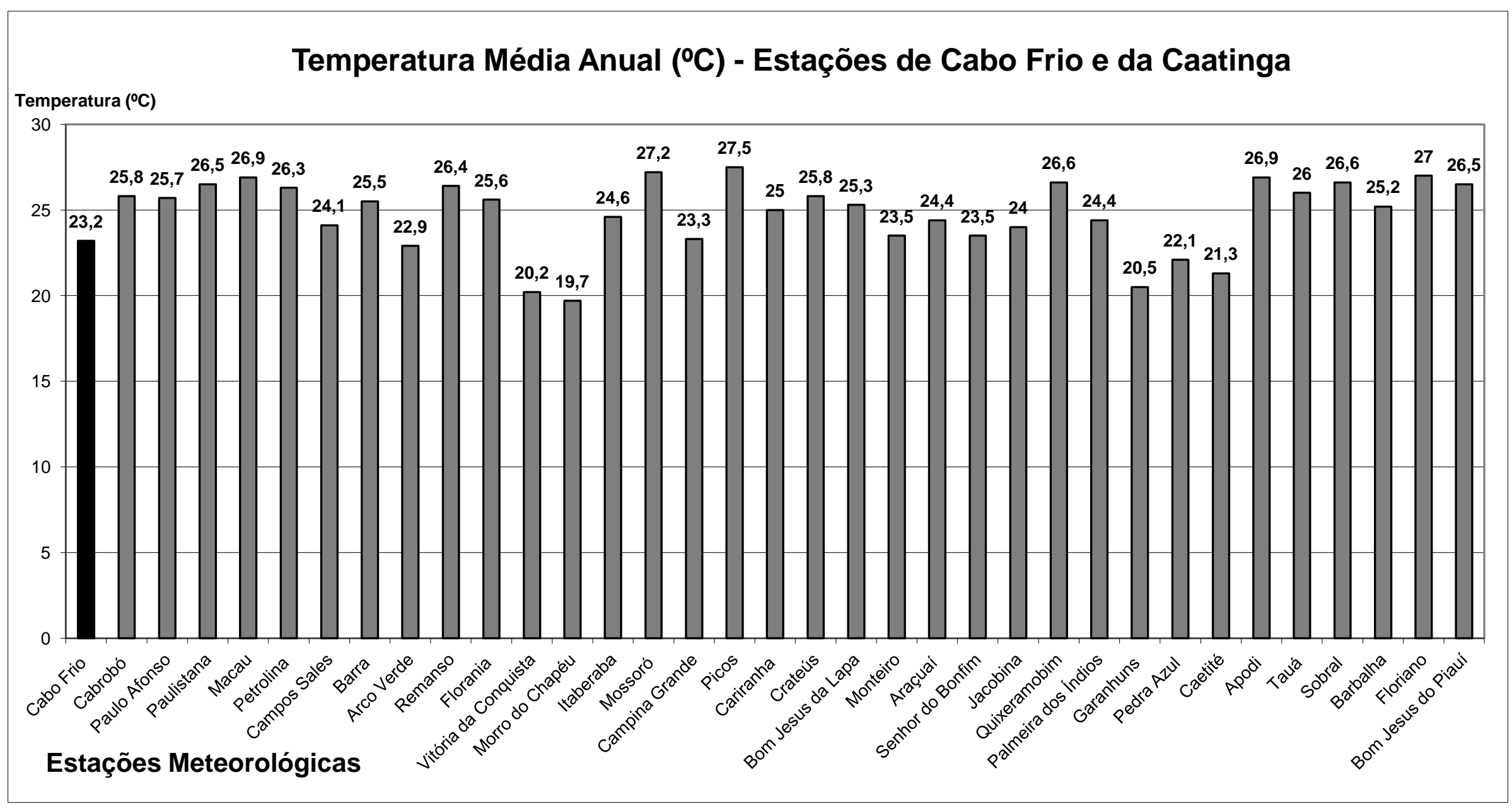

Figura 8: Temperatura média anual nas estações meteorológicas de Cabo Frio e da caatinga (Fonte: INMET, 2005) 
ANÁLISES MULTIVARIADAS:

Fazendo-se uma análise através de Box plot (figura 9), verifica-se que Cabo Frio e Iguaba, distantes entre si apenas $14 \mathrm{~km}$, têm precipitação considerada como outliers quando comparados com seu entorno. Já com a caatinga, a região de Cabo Frio se enquadra perfeitamente nos valores medianos, considerando precipitação, evaporação, insolação e umidade relativa do ar.

A análise de grupamentos confirmou a semelhança entre Cabo Frio e a região da caatinga, elegendo como locais mais semelhantes a Cabo Frio os municípios de Palmeira dos Índios, AL $(1,25)$; Araçuaí, MG $(2,17)$ Senhor do Bonfim $(2,40)$ e Jacobina, BA $(2,88)$ (figura 10$)$.

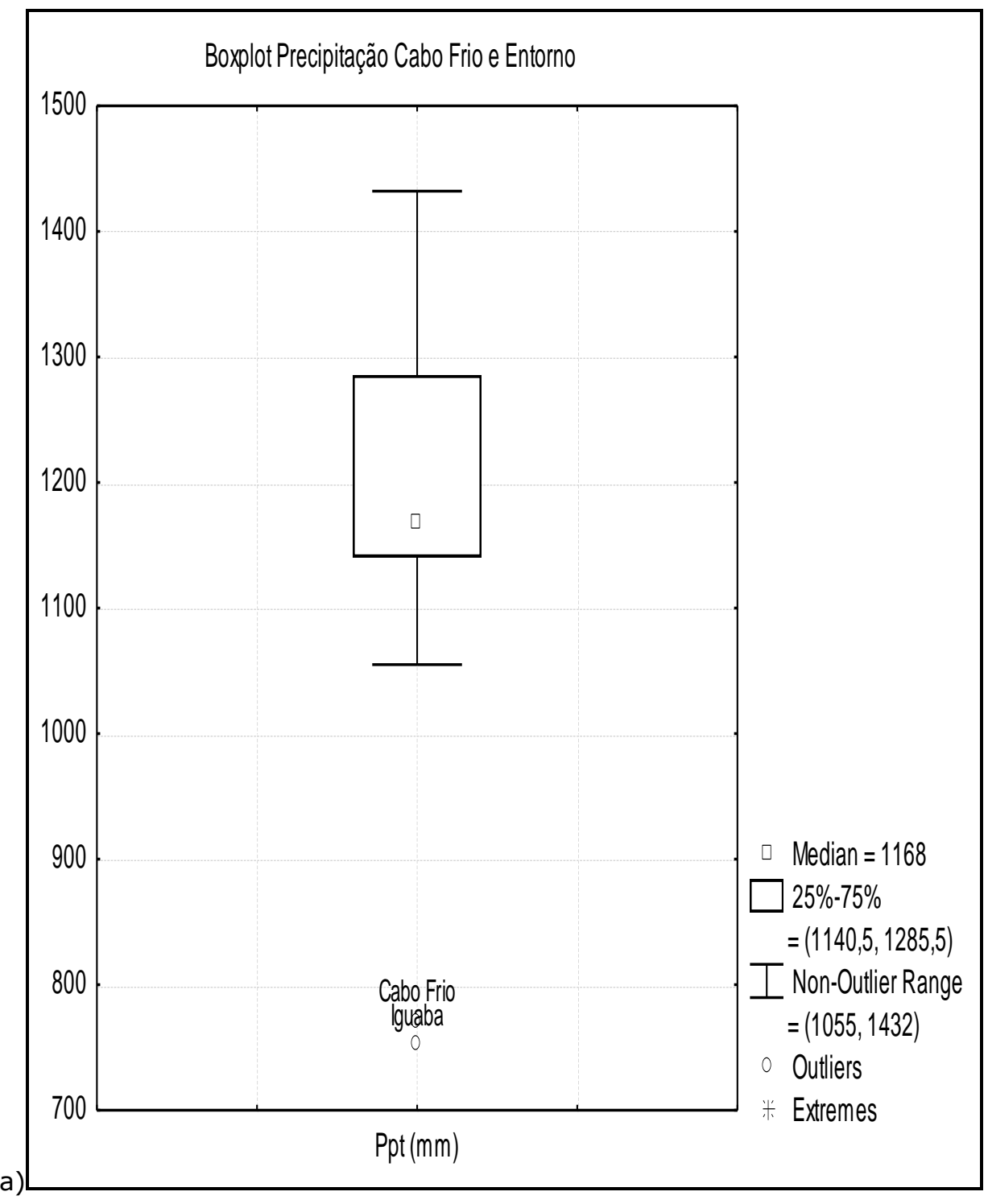




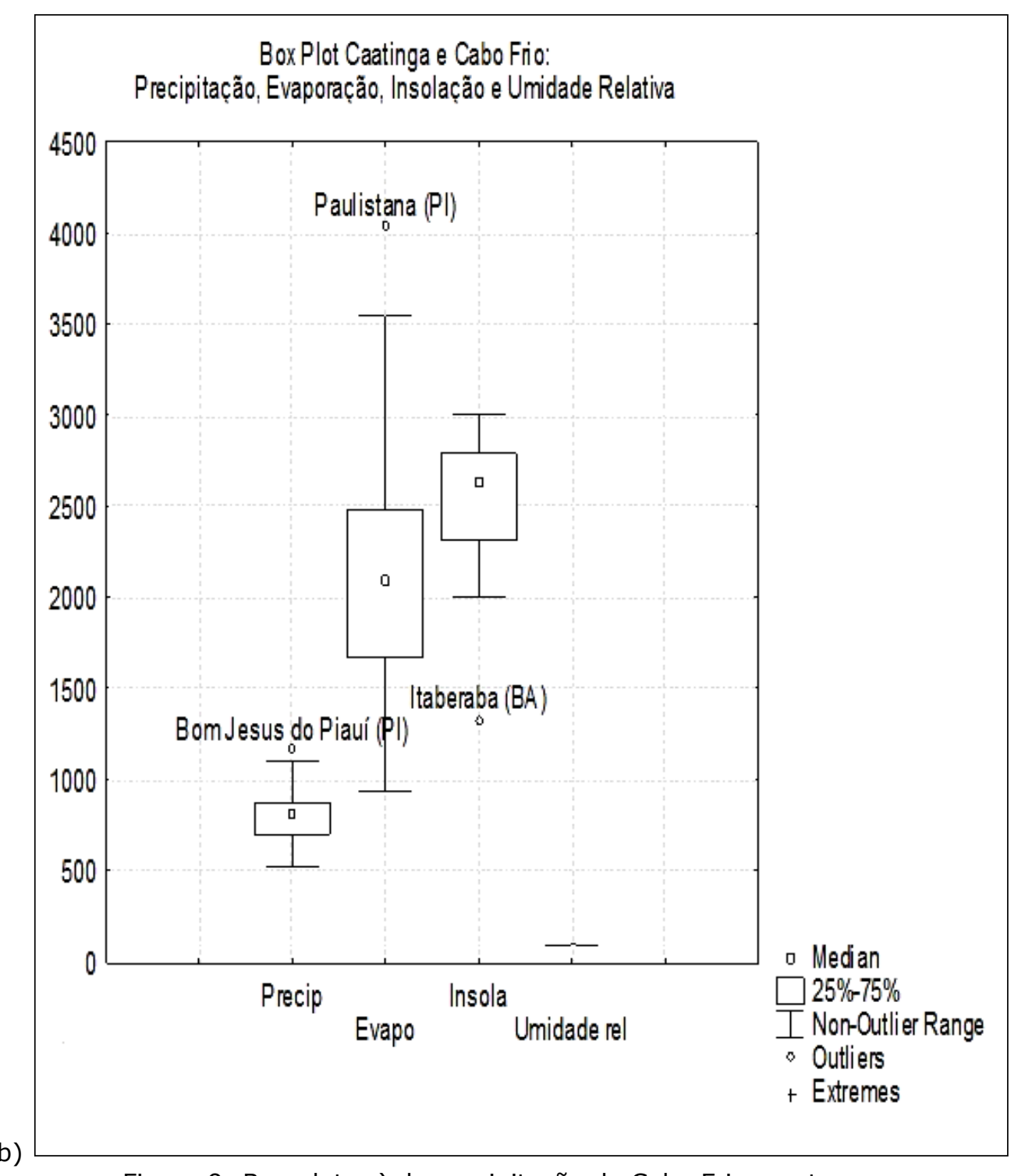

Figura 9: Box plot: a) da precipitação de Cabo Frio e entorno;

b) da precipitação, evaporação, insolação e umidade relativa do ar da Caatinga e Cabo Frio

As hipóteses de semelhança de clima entre Cabo Frio e a região da caatinga, inferidas por experimentados pesquisadores (Ab'Saber, 1973, 1977, 2003, Araujo, 2000, Barbiére, 1975, 1984, 1986, Nimer, 1989) careciam desta confirmação mais objetiva. Análises multivariadas deste tipo, aplicadas à fitossociologia, foram decisivas nos trabalhos de Prado (1991, 2000), e têm sido usadas para análises de clima em diversas escalas (Araújo, 2005; Fechine e Galvíncio, 2008; Guedes et al., 2010). 


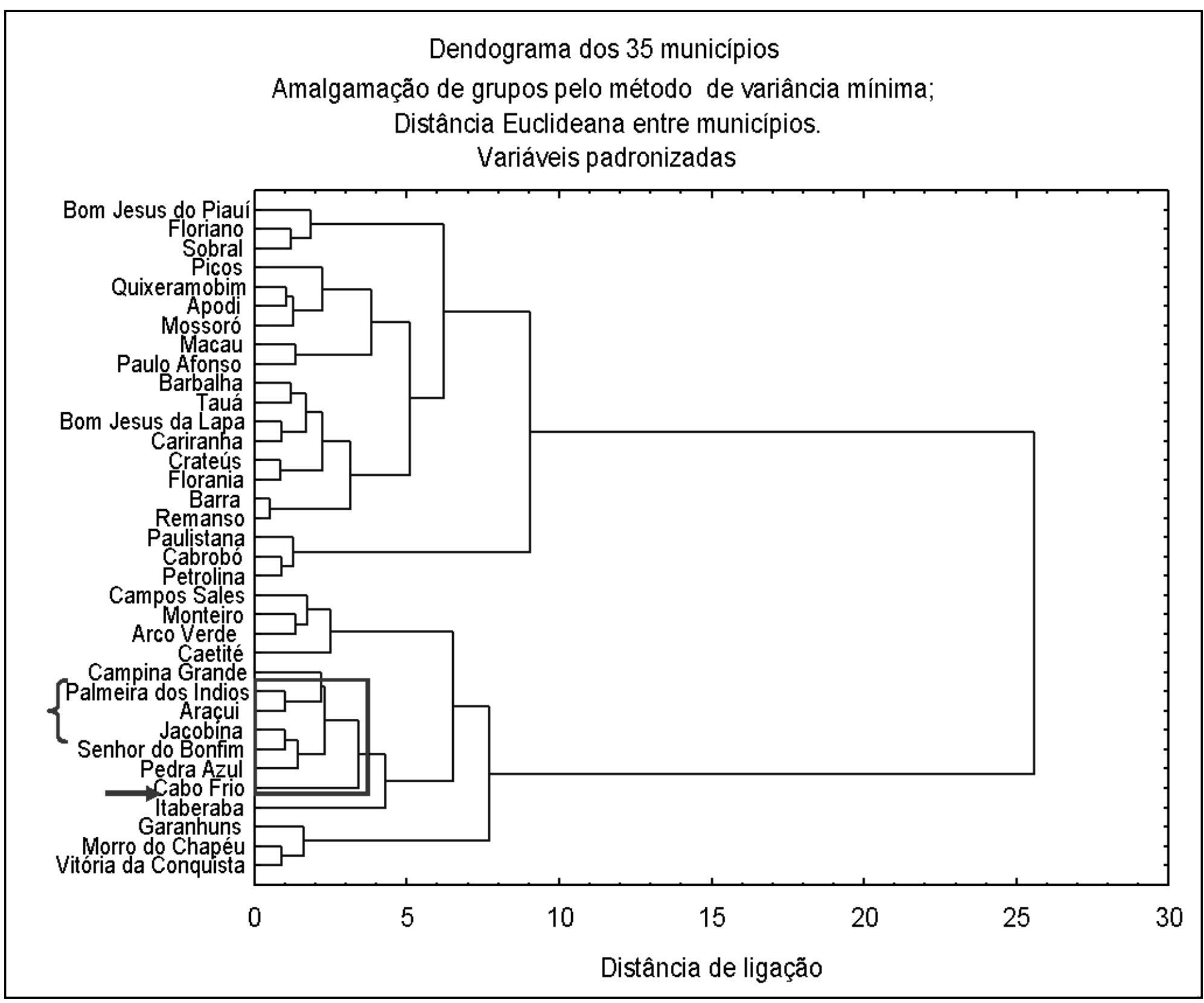


Distância Euclidiana de Cabo Frio aos municípios da Caatinga

C15=Senhor do Bonfim (BA); C21= Palmeira dos Índios (AL); C27=Jacobina (BA); C33=Araçuí (MG)

\begin{tabular}{|c|c|c|c|c|c|c|c|}
\hline C_1 & C_2 & C_3 & C_4 & C_5 & $C_{-} 6$ & C_7 & $C_{-} 8$ \\
\hline 4.63 & 4.01 & 6.38 & 5.01 & 4.17 & 4.22 & 4.50 & 3.55 \\
\hline C_9 & C_10 & C_11 & C_12 & C_13 & C_14 & _ & C_16 \\
\hline 3.14 & 4.31 & 3.71 & 4.18 & 3.27 & 3.20 & & 3.66 \\
\hline C_17 & C_18 & C_19 & C_20 & & C_22 & C_23 & C_24 \\
\hline 3.57 & 5.63 & 3.58 & 5.36 & & 4.30 & 3.94 & 4.27 \\
\hline C_25 & C_26 & & C_28 & C_29 & C_30 & C_31 & C_32 \\
\hline 4.36 & 3.92 & 000 & 4.58 & 3.83 & 4.48 & 3.48 & 3.81 \\
\hline & C_34 & C_35 & & & & & \\
\hline 17 & 3.10 & 0.00 & & & & & \\
\hline
\end{tabular}

Figura 10: Análise multivariada (Cluster com matriz de distância) comparando-se entre as estações meteorológicas de Cabo Frio e 34 estações da caatinga as variáveis: evaporação, insolação, precipitação e umidade relativa do ar 
As peculiaridades geológicas, geomorfológicas, oceanográficas e climáticas da região de Cabo Frio foram sintetizadas na figura 11. Muitas dessas peculiaridades têm origem na história paleoevolutiva da região, com flutuações climáticas (alternância de períodos mais quentes e úmidos e outros mais frios e secos) e consequentes variações do nível relativo do mar durante o Quaternário, com regressões marinhas durante os períodos glaciais e transgressões, principalmente holocênicas, durante os períodos interglaciais.

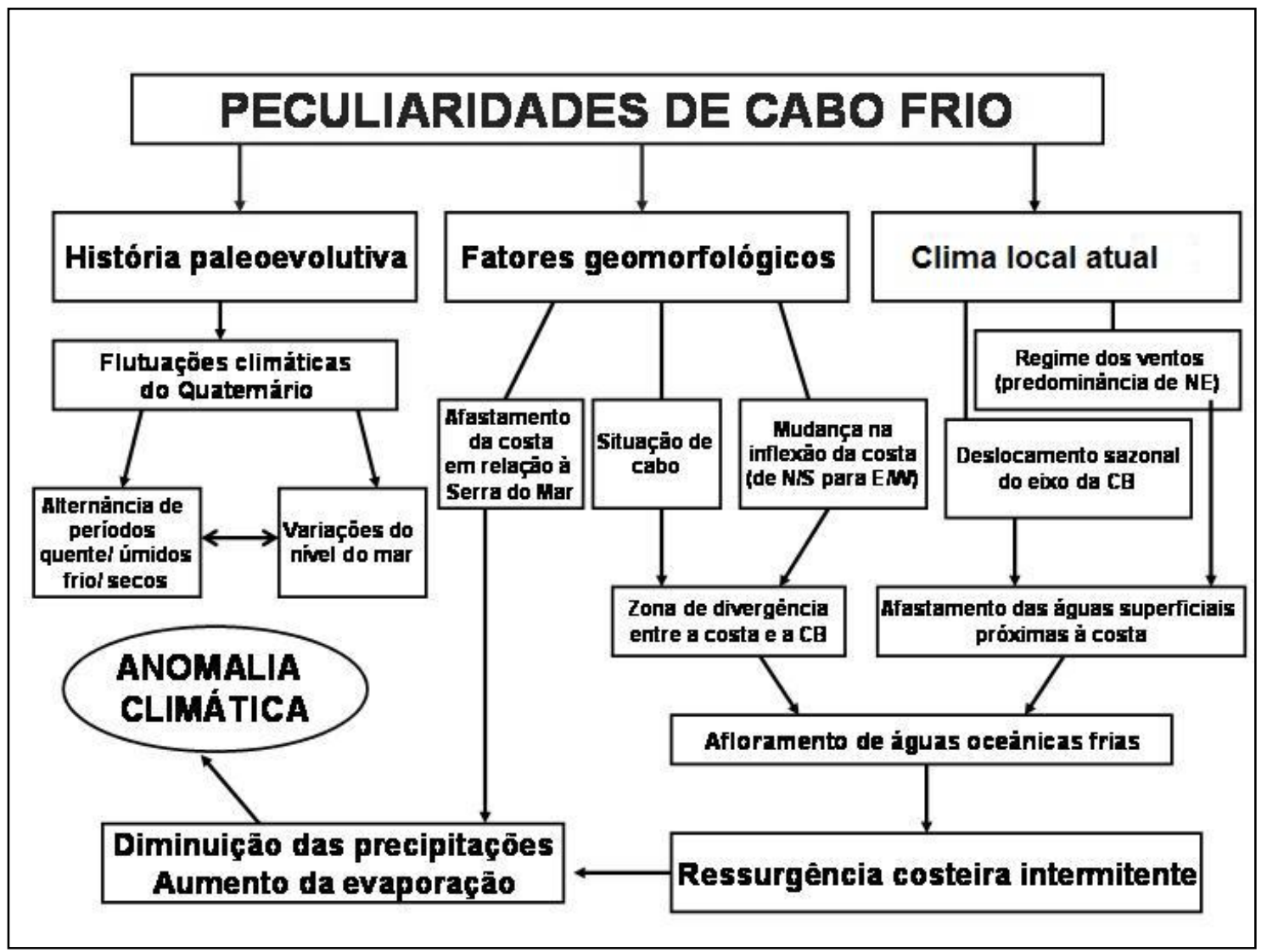

Figura 11: Peculiaridades geológicas, geomorfológicas, oceanográficas e climáticas da região de Cabo Frio

Fatores geomorfológicos locais como o fato de ser um cabo, associado à grande distância da linha de costa nesse local até a Serra do Mar (ponto do Estado do Rio de Janeiro em que a Serra do Mar está mais afastada do litoral), reduzem a possibilidade de formação de chuvas orográficas. Além disso, nesse ponto a plataforma continental é pouco extensa e existe a presença de um alto estrutural, sendo o local onde a costa brasileira muda da direção norte-sul para leste-oeste, inflexão que provoca uma zona de divergência entre a costa e a Corrente do Brasil (CB).

Esses fatores geológico-geomorfológicos, associados a características do clima local, como a predominância de fortes ventos de nordeste, os quais são fortalecidos durante a primavera-verão, e ao deslocamento sazonal da $C B$, permitem

- afastamento das águas superficiais próximas à costa e o afloramento de águas oceânicas frias. Essa ressurgência costeira intermitente influencia o clima local, com redução das precipitações e aumento da evaporação, criando a anomalia climática que foi comprovada pelos testes estatísticos.

\section{PALEOCLIMAS}

Em todas as amostras, os valores do índice de densidade arbórea (D/P) calculados (entre 0,2 e 0,8 ) pelas análises de fitólitos 
foram característicos de formações vegetais mais abertas, pouco arbóreas, com pequenas variações no decorrer do tempo.

Os resultados fitolíticos foram relacionados com outros estudos paleoambientais sobre a região (figura 12). Os valores dos índices $D / P$ sugerem que, no final do Pleistoceno (13.000 anos cal AP), a vegetação era menos arbórea que atualmente. De 13.000 a cerca de 6.000 anos cal AP, a tendência é de aumento da cobertura arbórea. Neste período, estudos de Andrade (2008) e Oliveira (2008) registraram episódios de ressurgência mais fracos. De 6.000 a 1.500 anos cal BP, a tendência é a diminuição da cobertura arbórea, e também há registros de ressurgência e episódios EI Niño mais intensos (Andrade, 2008; Oliveira, 2008). Dentro dessa fase, o período de menor densidade arbórea foi entre $6.000 \mathrm{e}$ 5.000 anos cal BP, quando, além dos menores índices $D / P$, também se verificou um enriquecimento do $\delta^{13} \mathrm{C}$ e um aumento da razão entre os fenóis $\mathrm{C} / \mathrm{V}$ das ligninas, característicos de uma abertura da vegetação. A partir de 1.500 anos cal BP, o sinal fitolítico já não registra variações e os estudos sobre a ressurgência apontam um período de grande variabilidade da mesma.

As variações no nível do mar, registradas a nível regional (costa leste do Brasil), não parecem ter relações diretas com as mudanças na cobertura vegetal de Cabo Frio. Estas mudanças parecem ser mais influenciadas por variações na intensidade da ressurgência, de âmbito local. Parece haver boa concordância entre os resultados dos estudos sobre a ressurgência e o sinal fitolítico, apesar de algumas diferenças devidas, sobretudo, à escala de tempo das mudanças que podem ser registradas pelos primeiros e a resposta da vegetação (registrada pela análise fitolítica) a essas mudanças. As análises fitolíticas registram mudanças na vegetação que podem ser a nível local, sem necessariamente estarem ligadas a grandes mudanças climáticas em escala mais regional.

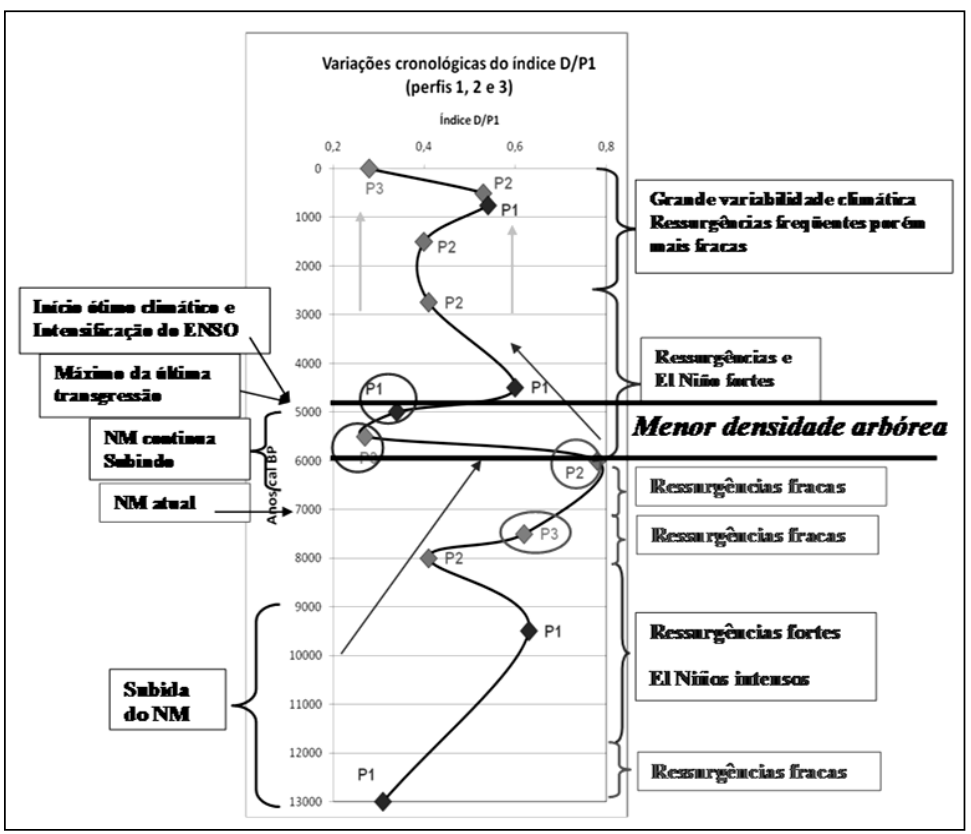

Figura 12: Índice $D / P$ durante o Holoceno, comparado com outros estudos paleoambientais na região de Cabo Frio

\section{CONCLUSÕES}

Das análises realizadas, conclui-se que Cabo Frio tem precipitação significativamente menor que o seu entorno, ao mesmo tempo em que se assemelha à caatinga quanto à precipitação, evaporação, temperatura do ar, insolação e umidade relativa do ar.

Comprova-se, assim, por análise numérica de dados climatológicos, a existência do "enclave" climático. Este contraste pluviométrico em relação ao restante do Estado do Rio de Janeiro proporciona dois climas distintos a uma reduzida distância: um clima tropical úmido, dominando o Estado, e um clima subúmido em Cabo Frio.

As razões que respondem pela existência desse enclave climático são múltiplas e complexas, destacando-se a flutuação climática ocorrida no Quaternário, que se 
observou no litoral leste (Ab'Saber, 1973) e as condições climáticas especiais da área. Estas peculiaridades climáticas têm sido explicadas por fatores como a grande distância da linha de costa até a Serra do Mar e a emergência de águas frias em uma costa dominada por correntes quentes (fenômeno da ressurgência), resultando na atenuação das precipitações e numa dinâmica climática diferenciada durante os meses de janeiro e fevereiro (Barbiére, 1975).

Estudos paleoambientais (análises fitolíticas) na região não indicam uma grande mudança no tipo de cobertura vegetal: a vegetação desde 13.000 anos cal AP foi sempre de tipo pouco arbórea (floresta xeromórfica), sugerindo que a vegetação local não atingiu a densidade arbórea característica das florestas úmidas do restante do litoral fluminense. Os resultados das análises fitolíticas foram correlacionados com outros estudos paleoambientais sobre a região. As variações no nível do mar, registradas a nível regional (costa leste do Brasil), não apresentaram relações diretas com as mudanças na cobertura vegetal de Cabo Frio. Estas mudanças parecem ser mais influenciadas por variações na intensidade da ressurgência, de âmbito local. Os resultados indicam que o enclave climático da região de Cabo Frio existe desde o início do Holoceno, com períodos relativamente mais ou menos úmidos, mas sempre com características mais áridas que o restante do litoral sudeste brasileiro.

\section{AGRADECIMENTOS}

Os autores gostariam de expressar os seus agradecimentos à Capes, pela concessão da bolsa de estágio doutoral no exterior, à FAPERJ, pelo suporte financeiro, à Dra. Guaciara dos Santos, pelas datações ${ }^{14} \mathrm{C}$ e à Marinha do Brasil e ao Inmet pela disponibilização dos dados meteorológicos. 


\section{REFERÊNCIAS BIBLIOGRÁFICAS}

AB'SABER, A. N. A organização natural das paisagens inter e subtropicais brasileiras. Geomorfologia, São Paulo, v. 41, 1973, p. 139.

AB'SABER, A. N. O mecanismo de desintegração das paisagens tropicais do Pleistoceno. Inter Fácies, v. 4, 1977, p. 1-19.

AB'SABER, A. N. Redutos de cactáceas, jardins da natureza. Scientific American Brazil, v. 19, dez. 2003.

ALEXANDRE, A., MEUNIER, J.D., MARIOTTI, A., SOUBIES, F. Late Holocene Phytolith and Carbon-Isotope Record from a Latosol at Salitre, South-Central Brazil. Quaternary Research, v. 51, n. 2, 1999, p. 187-194.

ANDRADE, M. M. Paleoprodutividade costeira da região de Cabo Frio, Rio de Janeiro, ao longo dos últimos 13.000 anos cal AP. Niterói, RJ, 2008. 275 p. Tese (Doutorado em Geoquímica), UFF, Niterói, RJ. 2008.

ARAUJO, D. S. D. Cabo Frio Region. In: DAVIS, S. D. H., V.H.; HERRERA-MACBRYDE, O.; VILLA-LOBOS, J. \& HAMILTON, A.C. (Ed.). Centers of Plant Diversity: a guide and strategy for their conservation: The Americas. Oxford: WWF/IUCN, 1997, v.3, p.373-375.

ARAUJO, D. S. D. Análise florística e fitogeográfica das restingas do Estado do Rio de Janeiro. Rio de Janeiro, 2000. 176 p. Tese (Doutorado em Ecologia), UFRJ, Rio de Janeiro. 2000.

ARAújO, S. M. B. Estudo da Variabilidade Climática em Regiões Homogêneas de Temperaturas Médias do ar no Rio Grande do Sul. 54p. Dissertação de Mestrado, Faculdade de Meteorologia, Universidade Federal de Pelotas, Pelotas, 2005.

BARBIÉRE, E. B. Ritmo climático e extração do sal em Cabo Frio. Rev. Bras. Geografia, v. 37, n. 4, p. 23-109, 1975.

BARBIÉRE, E. B. Cabo Frio e Iguaba Grande, dois microclimas distintos a um curto intervalo espacial. In: (Ed.). Restingas: origem, estrutura, processos. Niterói: CEUFF, p.3-13, 1984.

BARBIÉRE, E. B. Distribuição de pluviosidade ao longo do trecho Niterói-Cabo Frio (RJ). Ciência e cultura, v. 38, n. 7, p. 766-767, 1986.

BARBOSA, D. S. Sedimentação Orgânica na Lagoa Brejo do Espinho (Cabo Frio, RJ):
Composição e Implicações Paleoclimáticas. 2003. 90 p. Dissertação (Mestrado em Geoquímica), UFF, Niterói, RJ. 2003.

BREMOND, L., ALEXANDRE, A., PEYRON, O., GUIOT, J. Grass water stress estimated from phytoliths in West Africa. Journal of Biogeography, v. 32, 2005, p. 311-327.

CAMARGO, M. N. Guia de excursão de estudos de solos no Estado do Rio de Janeiro. In: SBCS, Reunião de Classificação, Correlação e Interpretação de Aptidão Agrícola de Solos, 1979, Campinas, p.77-246.

$\mathrm{COE}, \mathrm{H}$. H. G. Fitólitos como indicadores de mudanças na vegetação xeromórfica da região de Búzios/Cabo Frio, $R J$, durante o Quaternário. 2009. 300 p. Tese (Doutorado em Geologia e Geofísica Marinha), Lagemar, UFF, Niterói. 2009.

COE, H. H. G.; ALEXANDRE, A.; CARVALHO, C. N.. Les Phytolithes, Indicateurs de l'Évolution de la Végétation Xérophile de Búzios, Rio de Janeiro, Brésil, pendant le Quaternaire. Congrès de l'Ecole Doctorale de Sciences de l'Environnement, 2007. Marseille, France, 2007.

COE, H. H. G., ALEXANDRE, A., CARVALHO, C. N. Holocene Changes in Tree Cover Density at Cabo Frio (Rio de Janeiro, Brazil) infered from Soil Phytolith Assemblages. 7th International Meeting on Phytolith Research, 2008. Mar del Plata, Argentina. Centro de Geología de Costas y Del Cuaternario, 2008.

COE, H. H. G., AleXANDRE, A.; CARVAlHo, C. N. Mudanças na Densidade da Cobertura Arbórea na Região de Búzios/Cabo Frio, RJ, Brasil, durante o Holoceno inferidas através de Assembléias Fitolíticas extraídas de Solos. IV Congreso Argentino de Cuaternario y Geomorfología, XII Congresso da Associação Brasileira de Estudos do Quaternário, II Reunión sobre el Cuaternario de América del Sur, 2009. La Plata, Argentina, 2009.

COE, H. H. G., OSTERRIETH, M., BORRELI, N., SILVA, A. S., GOMES, J. G. Contributions of Phytolith Studies on the Identification of Soil Genesis and Environmental Changes in the São João River Basin, Rio de Janeiro, Brazil. 8th International Meeting on Phytolith Research, 2011. Ester Park, Colorado, USA, 2011.

COE, H. H. G., ALEXANDRE, A., CARVALHO, C. N., SANTOS, G. M., SILVA, A. S., SOUSA, L. O. F., LEPSCH, I. F. Changes in Holocene tree cover density in Cabo Frio (Rio de 
Janeiro, Brazil): Evidence from soil phytolith assemblages, Quaternary International, doi:10.1016/j.quaint.2012.02.04 4, 2012.

FARÁG, P. R. C. Estrutura do estrato arbóreo de mata litorânea semicaducifólia sobre solo arenoso no município de Búzios, RJ. 1999. 87 p. Dissertação (Mestrado. em Botânica), Museu Nacional, UFRJ, Rio de Janeiro. 1999.

FECHINE, J. A. L.; GALVÍNCIO, J. D. Análise das Precipitações Mensais da Bacia Hidrográfica do Rio Brígida no Semi-árido Pernambucano, usando o Método de Wards. Boletim Goiano de Geografia, v. 28, n. 2, p. 75-88, 2008.

GUEDES, R. V. S., LIMA, F. J. L., AMANANJÁS, J. C., BRAGA, C. C. Análise em Componentes Principais da Precipitação Pluvial no Estado do Piauí e Agrupamento pelo Método de Ward. Revista de Geografia, v.27, n.1, 218-233, 2010.

IBRAIMO, M. M., SCHAEFER, C. E., KER, J. C. Gênese e Micromorfologia de Solos sob Vegetação Xeromórfica (caatinga) na Região dos Lagos (RJ). R. Bras. Ciência do Solo, v. 28,2004 , p. $695-712$.

LIMA, H. C. Leguminosas arbóreas da Mata Atlântica. Uma análise da riqueza, padrões de distribuição geográfica e similaridades florísticas do Estado do Rio de Janeiro. Rio de Janeiro, 2000. 151 p. Tese (Doutorado em Ecologia), UFRJ, Rio de Janeiro. 2000.

MONIZ, A. C.; GRANDE, M. A.; OLIVEIRA, V. Solos do Trecho Cabo Frio-Xerém (RJ): Influência de regimes pluviais e de material de origem na pedogênese. Rev. Bras. Ciência do Solo, v. 14, 1990, p. 205-214.

MOONEY, H. A.; BULLOCK, S. H.; MEDINA, E. Seasonally dry tropical forests. Introduction. In: S. H. BULLOCK; MOONEY, H. A., MEDINA, E. (Ed.). Seasonally dry tropical forests. Cambridge Univ. Press, p.1-8, 1995.
NIMER, E. Climatologia do Brasil. 2 ed. Rio de Janeiro: IBGE, 1989.

OLIVEIRA, A. C. C. Registro de paleotemperaturas na plataforma continental de Cabo Frio, Rio de Janeiro, ao longo dos últimos 13.000 anos. Niterói, 2008. 205 p. Tese (Doutorado em Geoquímica), Universidade Federal Fluminense, Niterói. 2008.

ORTEGA, L. T. Variations paléohydrologiques et paléoclimatiques d'une région d'upwelling au cours de l'Holocene: enregistrement dans les lagunes cotières de Cabo Frio (État de RJ, Brésil). Paris, 1996Thèse de Doctorat (Variations paléohydrologiques et paléoclimatiques d'une région d'upwelling au cours de l'Holocene: enregistrement dans les lagunes cotières de Cabo Frio (État de RJ, Brésil)) - Terre, Océan, Espace, Paris 6, Paris. 1996.

PRADO, D. E. A critical evaluation of the floristic links between Chaco and Caatingas vegetation in South America. 1991. 173 p. Tese (Doutorado), Un. Saint Andrews, 1991.

PRADO, D. E. Seasonally Dry Forests of Tropical South America: from forgotten ecosystems to a new phytogeographic unit. $J$. Bot., v.37, n.3, p, 437-461, 2000.

RIZZINI, C. T. Tratado de Fitogeografia do Brasil. São Paulo: EDUSP, 1979.

SCHMITT, R. S. Late amalgamation in the crustal part of West Gondwana: new chronological data and the characterization of a Cambrian collisional orogeny in the Ribeira Belt (SE Brazil). Precambrian Research, v. 133, p. 29-61, 2004.

URURAHY, J. C. C. Nota sobre uma formação fisionômico-ecológica disjunta da estepe nordestina na área do Pontal de Cabo Frio, RJ. Rev. Bras. Geogr., v. 49, n. 4, p. 25-29, 1987.

VALENTIN, J. L. Analyse des paramètres hydrobiologiques dans la remontée de Cabo Frio (Brésil). Marine Biology, v. 82, 1984, p. 259-276. 
